EESTI NSV TEADUSTE AKADEEMIA TOIMETISED 1955. IV kd., nr. 2 ИЗВЕСТИЯ АКАДЕМИИ НАУК ЭСТОНСКОИ ССР 1955. Том IV, № 2

\title{
ВЫБОР ЦЕНТРАЛИЗОВАННЫХ ЭНЕРГОНОСИТЕЛЕЙ ДЛЯ ГОРОДА ТАЛЛИНА
}

\author{
Л. э. ВАИК, \\ кандидат технических наук
}

Основным направлением развития советской энергетики является централизация энергоснабжения, осуществляемая комплексно путем электрификации всей страны, газификации и централизованного теплоснабжения городов и промышленности.

Централизованные виды энергии или энергоносители - электроэнергия, газ и горячая вода - имеют различные технико-экономические показатели, с одной стороны, а с другой стороны, они неодинаковым образом соответствуют требованиям, предъявляемым им со стороны потребителей. Из этого следует, что при выборе централизованных энергоносителей и определении области их рационального применения необходимо учитывать их эффективность в народнохозяйственном отношении.

Для некоторых процессов рациональный вид энергии или энергоноситель являются бесспорными. Так, например, для силовых процессов и нужд освещения наиболее целесообразной является электроэнергия, а для процессов отопления и вентиляции - горячая вода из тепловой системы. В остальных случаях нельзя a priori предопределить рациональные энергоносители, поскольку выбор их зависит от ряда местных факторов - от типа и размещения энергогенерирующих установок, от энергетического баланса города и окружающего района, от вида энергетических ресурсов н т. д.

В условиях города Таллина такими процессами, для которых необходимо произвести выбор рациональных энергоносителей, являются:

а) в промышленности - высокотемпературные процессы (плавильные, термические и нагревательные печи главным образом на машиностроительных заводах), для которых централизованными энергоносителями могут являться электроэнергия и газ;

б) в коммунальном хозяйстве - высокотемпературные процессы (приготовление пищи), для которых энергоносителями могут являться электроэнергия и газ, и низкотемпературные процессы (коммунальное и бытовое горячее водоснабжение), для которых централизованными энергоносителями могут служить газ и горячая или перегретая вода. 


\section{1. Методика выбора централизованных энергоносителей}

Выбор целесообразных централизованных энергоносителей должен основываться на положениях общего комплексного энергетического метода исследования. Основным положением этого метода является выявление всех взаимосвязей между отдельными звеньями энергетического хозяйства и отраслями народного хозяйства - от энергетических ресурсов до потребителей включительно. Әти взаимосвязи необходимо вскрыть в первую очередь по технико-экономическим показателям схемы энергоснабжения, то есть по коэффициенту полезного действия и расходу топлива, по капиталовложениям и по эксплуатационным расходам. Однако эти показатели позволяют сравнивать сопоставляемые энергоносители только количественно. Кроме количественной оценки следует провести также и качественный анализ, дать оценку положительных и отрицательных характеристик каждого энергоносителя. Сопоставление преимуществ и недостатков сравниваемых энергоносителей позволяет наиболее полно определить рациональные энергоносители для отдельных процессов.

Сущность разработапной методики выбора энергоносителей состоит в следующем.

Энергоносители сравниваются по общему энергетическому коэффициенту полезного действия всей энергетической цепи, по полному расходу исходного энергетического ресурса - топлива, по полным капиталовложениям и по полным эксплуатационным расходам.

Полные технико-экономические показатели определяются по отдельным элементам энергетического хозяйства - по топливодобыче, энергогенерирующей установке, транспорту, распределению и вводу энергии и потребительской аппаратуре.

Схема описанной методики представлена в таблице 1.

Показатели расхода топлива, капиталовложений и эксплуатационных расходов отнесены на одну мегакилокалорию полезно используемого тепла.

\section{2. Выбор энергоносителей для высокотемпературных процессов}

Как было указано, рациональными видами энергии или энергоносителями для высокотемпературных процессов могут являться электроэнергня и газ. Для сопоставления эффективности электроэнергии и газа необходимо правильно определить тип, ориентировочную мощность и месторасположение энергогенерирующих установок, в частности тин и месторасположение источника электроэнергии.

Целесообразными источниками электроэнергии для электроснабжения в условиях Таллина являются теплоэлектроцентрали (ТЭЦ) в городе и конденсационные электростанции (КЭС) на месте добычи топлива. Целесообразность сооружения ТЭЦ в Таллине для электро- и теплоснабжения города бесспорна, поэтому основным источником получения электроэнергии для силовых и осветительных процессов является теплоэлектроцентраль. Для выяснения участия городской ТЭЦ в покрытии электрической нагрузки высокотемпературных процессов необходимо исследовать структуру энергоснабжения Таллина, а также всей Эстонской ССР. По соот- 


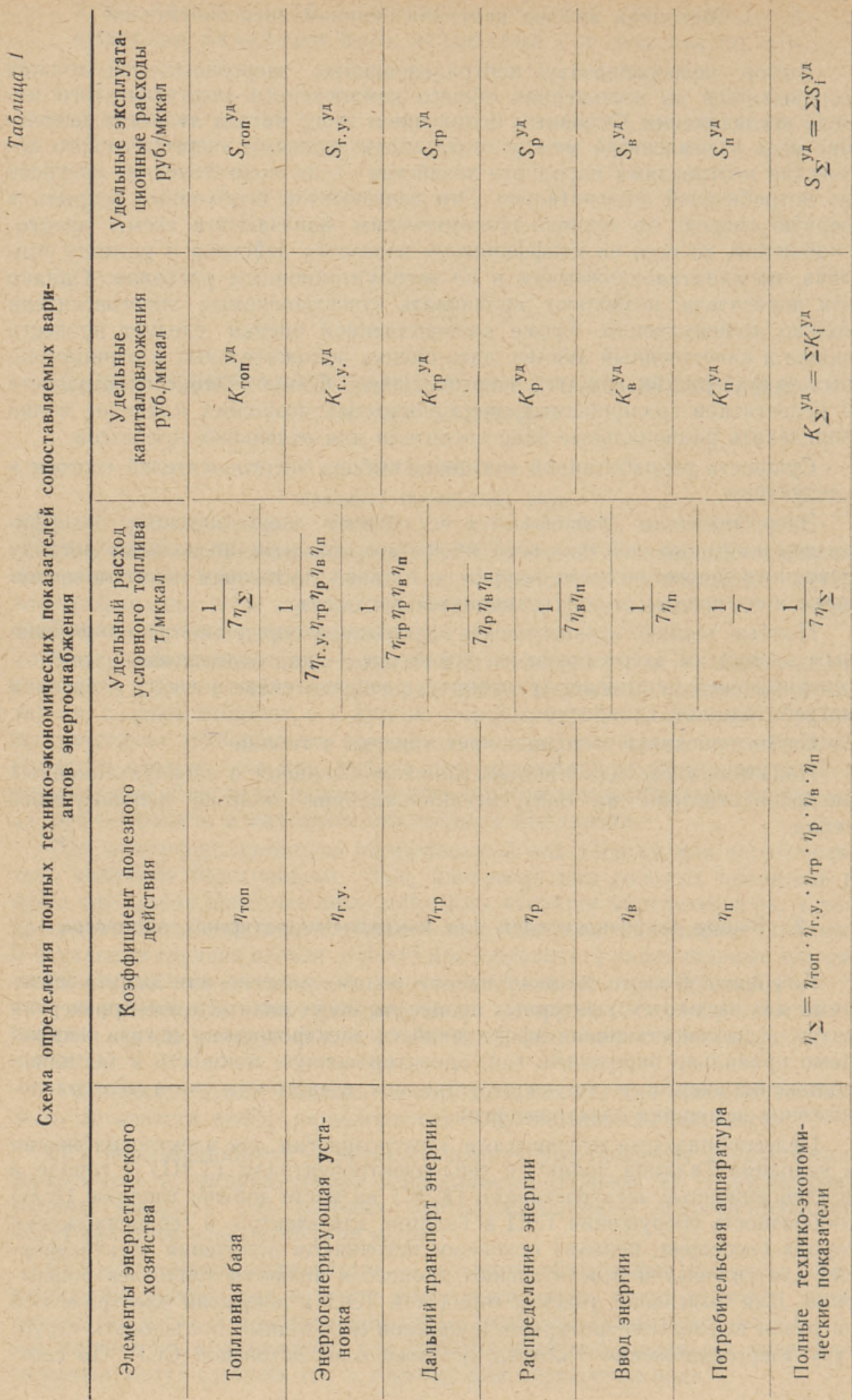


ветствующим расчетам структура тепло- и электропотребления Таллина характеризуется следующими неравенствами:

$$
\begin{gathered}
N_{\text {с }+ \text { o }}<y_{\text {тэц }} Q_{\text {тэц }}{ }^{\text {час }}, \\
N_{\text {с }+ \text { o+в }}>y_{\text {тэц }} Q_{\text {тэц }}{ }^{\text {час }},
\end{gathered}
$$

где

$N_{\text {c+o }}$ - суммарная электрическая нагрузка силовых и осветительных процессов, мвт;

$N_{\text {с+о+в }}$ - то же, с учетом высокотемпературных процессов, мвт;

$Q_{\text {тәц }}{ }^{\text {час }}$ - суммарная расчетная тепловая нагрузка ТЭЦ, мккал/час;

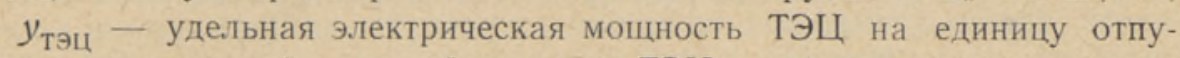
скаемой тепловой нагрузки ТЭЦ, мвт/мкка,т/час.

Приведенные соотношения показывают возможность полного покрытия потребности в электроэнергии силовых и осветительных процессов и даже частично высокотемпературных процессов за счет возможной суммарной электрической мощности ТЭЦ на базе теплового потребления города.

Однако, несмотря на это, при разрешении вопросов выбора энергоносителей для высокотемпературных процессов в коммунальном хозяйстве и в промышленности следует ориентироваться на получение электроэнергии от конденсационных электростанций. Дело в том, что в условиях тесных связей энергетики Таллина с энергетикой всей Эстонской ССР, особенно по линии электроснабжения и при структуре энергопотребления в электроэнергетической системе республики, которая, по соответствующим расчетам, характеризуется неравенством

$$
N_{\mathrm{c}+\mathrm{o}}>y_{\text {тэц }} Q_{\text {Тэц }}{ }^{\text {"ас }}+N_{\Gamma},
$$

где $N_{\Gamma}$ - суммарная мощность гидроэлектростанций (ГЭС) Эстонской ССР в мвт, - электрификация высокотемпературных процессов всегда связана с необходимостью в дополнительной конденсационной мощности в системе.

Учитывая вышеизложенное, схема энергоснабжения при электрификации высокотемпературных процессов состоит из следующих элементов:

a) топливной базы - сланцевый бассейн; топливо - сланец III сорта;

б) энергогенерирующей установки - конденсационная электростанция, оборудованная турбоагрегатами типа ВК-50 или ВК-100 высокого давления;

в) транспорта энергии - высоковольтная линия электропередачи с напряжением в 110 кв; расстояние КЭС от города порядка 150 км;

г) распределения энергии - распределительная высоко- и низковольтная сеть в городе с напряжением в 6 кв и 380/220 в вместе с трансформаторными подстанциями;

д) ввода энергии - электрические вводы в дом (в коммунальном хозяйстве) и домовая разводка;

е) потребительской аппаратуры - в зависимости от категории потребителей. В промышленности - плавильные, термические и нагревательные электропечи, в коммунальном хозяйстве - электроплиты для приготовления пищи.

Схема энергоснабжения при газификации высокотемпературных процессов, учитывая, что основным источником получения газа является газосланцевый завод в Кохтла-Ярве, состоит из следующих элементов:

a) топливной базы - сланцевый бассейн; топливо - сланец II сорта; Ярве;

б) энергогенерирующей установки -- газосланцевый завод в Кохтла- 
в) транспорта энергии - дальний газопровод длиной $150 \mathrm{kм;}$

г) распределения энергии - распределительная газопроводная сеть среднего и низкого давления вместе с газгольдером и регуляторными станциями;

д) ввода энергии - вводы и внутренняя газопроводка с газовыми счетчиками;

е) потребительской аппаратуры: в промышленности - плавильные, термические и нагревательные печи на газе, в коммунальном хозяйстве газовые плиты для приготовления пищи.

Сопоставляемые технико-экономические показатели по обеим схемам энергоснабжения высокотемпературных процессов приведены в таблице 2 .

Таблица 2

Сравнительные технико-экономические показатели схем электрификации и газификации высокотемпературных процессов

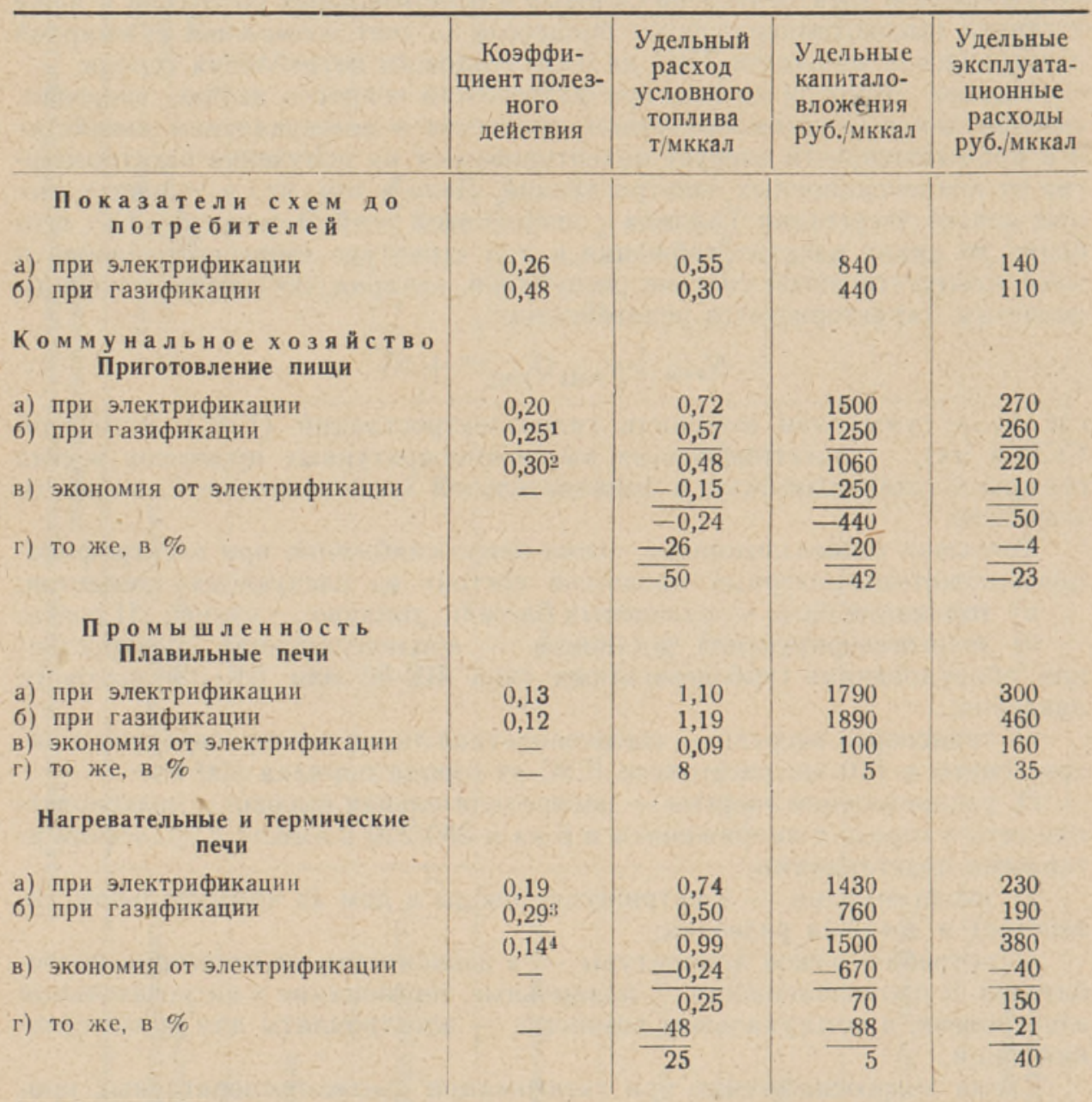

1 При кпд прибора $\eta_{\mathrm{n}}=0,55$.

2 При кпд прибора $\eta_{\mathrm{n}}=0,65$.

3 При использовании отходящих газов.

4 Без использования отходящих газов. 
В таблице 2, кроме полных показателей, приведены также и соответствующие показатели без учета потребительской аппаратуры, то есть технико-экономические показатели подведенной энергии (электроэнергии и газа) на единицу тепла в газе или в электроэнергии.

Как видно из таблицы, газ у потребителя по всем техникоэкономическим показателям в основном более эффективен, чем электроэнергия.

Однако получение полезного тепла из газа связано с процессом горения, а следовательно, с потерями тепла в отходящих газах, от неполноты сгорания и потерями в окружающую среду вследствие высокой температуры горения газа (порядка $1600-1800^{\circ} \mathrm{C}$ ). Получение же полезного тепла из электроэнергии происходит путем нагрева; поэтому при использовании электроэнергии отсутствуют или резко снижаются потери, специфичные для получения полезного тепла путем сжигания газа. Из этого следует, что единица тепла в газе, подведенная к печи, дает меньший полезный эффект, чем та же единица тепла в виде электроэнергии. Это сильно влияет на сравнительную эффективность применения газа и электроэнергии.

В коммунальном хољяйстве, бесспорно, более эффективным методом энергоснабжения высокотемпературных процессов (приготовления пищи) является газификация, что видно по всем технико-экономическим показателям даже при очень низком кпд потребительского прибора $\left(\eta_{\mathrm{n}}=0,55\right)$.

При плавильных печах в промышленности разница в кпд потребительской аппаратуры столь велика, что электрификация этих процессов является более эффективной, чем газификация. Этот вывод подтверждается также и качественными преимуществами электроэнергии перед газом меньший угар металла, быстрота плавки, точность регулирования температур, легкость контроля и обслужнвания, компактность, лучшие санитарные условия работы и т. д.

При нагревательных и термических печах электроэнергия имеет преимущество перед газом только в тех случаях, если при газификации печей не используются отходящие газы. При использовании отходящих газов для подогрева воздуха применение газа в этих печах по технико-экономическим показателям является более эффективным.

Кроме того, некоторые факторы указывают на целесообразность значительно более широкого внедрения в ближайшее время газа в промышленность и в быт. Напряженное положение с балансом цветных металлов и задача полного удовлетворения электроэнергией силовых и осветительных процессов всех отраслей народного хозяйства при одновременном значительном росте электропотребления ограничивают возможности использования электроэнергии в тех процессах, в которых могут быть применены другие централизованные энергоносители, в данном случае газ. При указанных трудностях, связанных с электроснабжением высокотемпературных процессов, применение для этих целей газа обеспечивает дальнейшее повышение уровня энергоснабжения. Применение газа, уступающего по своим качествам электроэнергии, имеет огромные народнохозяйственные преимущества перед непосредственным сжиганием твердого и жидкого топлива в промышленных печах и в быту. Газификация обеспечит переход на централизованное энергоснабжение, переход на местное низкокалорийное топливо - сланец. Существенным является также и то, решаются ли вопросы энергоснабжения для существующих или для вновь сооружаемых промышленных предприятий и новых технологических процессов. Для существующих предприятий газ должен быть принят в качестве основного энергоносителя для промышленных печей, потому что перевод печей на газ не требует больших расходов, в то время как установка электропечей требует значительных капиталовложений. 


\section{3. Выбор энергоносителей для низкотемпературных процессов}

Возможными способами централизованного энергоснабжения низкотемпературных процессов являются: теплофикация на базе ТЭЦ в городе, централизованное теплоснабжение на базе районных отопительных котельных в отдаленных от ТЭЦ районах и газификация на базе газогенераторной установки, находящейся на месте добычи топлива.

Схема энергоснабжения при теплофикации процессов горячего водоснабжения состоит из следующих элементов:

a) топливной базы - сланцевый бассейн; топливо - сланец III сорта;

б) транспорта топлива - железнодорожный транспорт сланца III сорта для выработки тепла, а также соответствующего количества электроэнергии в городе;

в) энергогенерирующей установки - теплоэлектроцентраль (ТЭЦ), оборудованная турбинами типа АТ-12;

г) распределения энергии - тепловые магистральные и распределительные (квартальные) сети; энергоноситель - перегретая вода с расчетной температурой воды $130^{\circ} \mathrm{C}$ и обратной $70^{\circ} \mathrm{C}$;

д) ввода энергии - тепловые вводы в дом и домовая разводка;

е) потребительской аппаратуры - при закрытой системе теплоснабжения - водо-водяные подогреватели; при открытой системе аппаратуры не имеется.

Схема энергоснабжения при централизованном теплоснабжении состоит из тех же элементов, с той лишь разницей, что энергогенерирующей установкой вместо ТЭЦ является районная отопительная котельная с расчетной тепловой нагрузкой в среднем 12 мккал/час.

Схема энергоснабжения при газификации низкотемпературных процессов в случае сопоставления со схемой теплоснабжения от районных котельных в основном та же, что и при газификации высокотемпературных процессов, только потребительскими аппаратами в данном случае являются газовые водогреи и ванные колонки.

Однако при схеме теплофикации энергогенерирующая установка вырабатывает, кроме тепла, также и электроэнергию. Поэтому для сопоставления схем теплофикации и газификации необходимо схему газификации дополнить элементами прозводства электроэнергии. Наиболее целесообразным вариантом получения электроэнергии в этом случае является получение ее от мощной КЭС, находящейся в районе топливной базы. Таким образом, дополнительными элементами схемы газификации по сравнению со схемой теплофикации являются:

а) топливная база - сланцевый бассейн; топливом для выработки электроэнергии является сланец III сорта;

б) энергогенерирующая установка - КӘС в районе топливной базы, оборудованная турбинами типа ВК-50 или ВК-100. Выработка электроэнергии. на 1 мккал полезно использованного тепла должна составлять 420 квтч с учетом потерь в высоковольтных линиях электропередачи;

в) транспорт энергии - высоковольтная линия электропередачи с напряжением в 110 кв, длиной 150 км.

Сравнительные технико-экономические показатели сопоставляемых схем энергоснабжения приведены в таблице 3 , причем все технико-экономические показатели отнесены на одну мегакилокалорию полезно использованного у потребителей тепла.

Как видно из таблицы 3 , газификация низкотемпературных процессов для осуществления централизованного горячего водоснабжения по сравнению с централизованным теплоснабжением от районных котельных менее эффективна уже до потребителя (без учета потребительской аппа- 
Сравнительные технико-экономические показатели схем газификации, теплофикации н централизованного теплоснабжения низкотемпературных процессов

\begin{tabular}{|c|c|c|c|c|c|}
\hline . & & $\begin{array}{c}\text { Коэффи- } \\
\text { циент } \\
\text { полезного } \\
\text { действия }\end{array}$ & $\begin{array}{c}\text { Удельный } \\
\text { расход ус- } \\
\text { ловного } \\
\text { топлива } \\
\text { т/мккал }\end{array}$ & $\begin{array}{c}\text { Удельные } \\
\text { капитало- } \\
\text { вложения } \\
\text { руб./мккал }\end{array}$ & $\begin{array}{c}\text { Удельные } \\
\text { эксплуата- } \\
\text { ционные } \\
\text { расходы } \\
\text { руб./мккал }\end{array}$ \\
\hline & Показатели & схем до по & ребителей & & \\
\hline & при газификации & 0,48 & 0,30 & 460 & 115 \\
\hline & $\begin{array}{l}\text { при централизованном тепло- } \\
\text { снабжении }\end{array}$ & 0,58 & 0,25 & 320 & 90 \\
\hline
\end{tabular}

Сравнение схем газификации и централизованного теплоснабжения процессов горячего водоснабжения
а) при газификации
б) при централизованном тепло- снабжении

\begin{tabular}{c|c}
0,41 & 0,35 \\
0,58 & 0,25 \\
- & 0,10 \\
- & 29
\end{tabular}

\begin{tabular}{r|}
590 \\
320 \\
-270 \\
46
\end{tabular}
140 теплоснабжения
г) то же, в \%

Сравнение схем газификации и теплофикации процессов горячего водоснабжения
a) при газификации
б) при теплофикации
в) экономия от теплофикации
г) то же, в \%

\begin{tabular}{c|c}
0,36 & 0,53 \\
0,53 & 0,37 \\
- & 0,16 \\
- & 30
\end{tabular}

\begin{tabular}{r|r}
820 & 180 \\
480 & 100 \\
340 & 80 \\
42 & 44
\end{tabular}

Сравнение раздельной и комбинированной схем теплоснабжения процессов горячего водоснабжения
а) при централизованном тепло- снабжении от районных котель- ных
б) при теплофикации
в) экономия от теплофикации
г) то же, в \%

\begin{tabular}{c|c}
0,45 & 0,43 \\
0,53 & 0,37 \\
- & 0,06 \\
- & 14
\end{tabular}

\begin{tabular}{r|r}
550 & 130 \\
480 & 100 \\
70 & 30 \\
13 & 23
\end{tabular}

ратуры) по всем технико-экономическим показателям. При полных схемaх энергоснабжения эффективность газификации еще уменьшается, потому что добавляются дополнительные расходы на потребительскую аппаратуру, которые при теплоснабжении от районных котельных почти полностью отсутствуют. Применение горячей воды вместо газа как энергоносителя обеспечивает уменьшение расхода топлива примерно на $30 \%$, капиталовложений на $45 \%$ и эксплуатационных расходов на $35 \%$.

Переход от централизованного теплоснабжения к теплофикации обеспечит дополнительную экономию в размере $13-25 \%$. Из этого следует, чтө наиболее целесообразным энергоносителем для низкотемпературных процессов, а именно процессов горячего водоснабжения в коммунальном хозяйстве и в промышленности, особенно в районах новой застройки, является горячая вода, получаемая в первую очередь от ТЭЦ. В районах, находящихся вне зоны действия тепловых сетей ТЭЦ, централизованное горячее водоснабжение целесообразно осуществить от районных котельных, сооружаемых для покрытия отопительно-вентиляционного теплопотребления. 
На эффективность теплофикации по сравнению с газификацией указывает и то, что газификация процессов горячего водоснабжения в районах действия теплофикационных сетей уменьшает суммарную тепловую нагрузку ТЭЦ, а, соответственно, также и теплофикационную электрическую мощность ТЭЦ. Это значит, что для покрытия графика электрической нагрузки в электроэнергетической системе Эстонской ССР необходимо увеличить конденсационную мощность за счет уменьшения теплофикационной мощности.

Что касается районов существующей застройки, то здесь следует учитывать следующие факторы, говорящие в пользу газификации.

1. Сплошная газификация центральной части Таллина в настоящее время уже проводится, и прокладка газовых магистралей в основном заканчивается в ближайшие годы. В то же время осуществление теплофикации находится еще в начальной стадии. Из этого следует, что некоторые районы газификации долгое время не будут охвачены теплофикационными сетями.

2. Газификация процессов горячего водоснабжения, являясь менее эффективной по сравнению с централизованным теплоснабжением, все же имеет огромные преимущества перед децентрализованным теплоснабжением, так как позволяет значительно повысить уровень бытового обслуживания населения.

Поэтому в ближайшее время низкотемпературные процессы горячего водоснабжения временно следует газифицировать. При этом предпочтение следует отдать в данном случае централизованному горячему водоснабжениіо от одной крупной газовой установки в доме, несмотря на некоторые неудобства в эксплуатации данной установки. Дело в том, что только в этом случае можно наиболее полно обеспечить органический переход к более высокому уровню в развитии энергетики Таллина - от газификации к теплофикации процессов горячего водоснабжения. Это положение подтверждается и тем обстоятельством, что в настоящее время из-за несовершенства конструкции газовых водогреев, они не выпускаются в необходимом количестве и поэтому в Таллине сейчас практически не устанавливаются.

\section{4. Выводы и рекомендации}

1. Целесообразными видами энергии или энергоносителями в условиях города Таллина являются электроэнергия, газ и горячая вода от ТЭЦ и отопительных котельных.

2. Высокотемпературные процессы в промышленности в части плавильных печей целесообразно электрифицировать. Это позволит, кроме получения экономии топлива, капитальных вложений и эксплуатационных расходов, повысить также качество выплавляемого металла, ускорить процесс плавки и облегчить обслуживание плавильных печей.

3. Другие высокотемпературные процессы в промышленности - в нагревательных и термических печах - целесообразно газифицировать. Это обеспечит значительную экономию топлива $(\sim 50 \%)$, капиталовложений $(\sim 90 \%)$ и эксплуатационных расходов $(\sim 20 \%)$, по сравнению с электрификацией этих процессов, и позволит заменить жидкое и дальнепривозное топливо местным топливом - сланцевом газом. Основным требованием при этом является использование отходящих газов с целью повышения общего энергетического кпд установок.

4. Высокотемпературные процессы в коммунальном хозяйстве - приготовление пищи - следует ориентировать на газификацию, которая по сравнению с электрификациецй этих процессов эффективна по всем основ- 
ным технико-экономическим показателям. Кроме того, это позволит заменить дрова и каменный уголь сланцевым газом.

5. Основным целесообразным направлением в централизации энергоснабжения низкотемпературных процессов - процессов горячего водоснабжения - бесспорно является теплофикация, а в районах, отдаленных от ТЭЦ, централизованное теплоснабжение от районных или групповых котельных.

6. Газификация низкотемпературных процессов не является эффективной не только по технико-экономическим показателям, но также и потому, что уменьшает выработку электроэнергии по теплофикационному циклу и тем самым вызывает необходимость увеличения мощности и выработку электроэнергии на конденсационных станциях.

7. Низкотемпературные процессы - горячее водоснабжение - в районах существующей застройки, отдаленных от будущих ТЭЦ, или районах, теплофикация которых намечена не в первую очередь, следует в ближайшее время газифицировать. Поскольку эти районы в дальнейшем будут теплафицированы, то для обеспечения органического перехода от газификации к теплофикации желательно при газификации предвидеть централизованное 'горячее водоснабжение от одной крупной домовой установки.

Ннститут энергетики

Академци наук Эстонской ССР
Поступила в редакцию

7 XII 1954 